\title{
Sports Medicine in times of COVID
}

\section{La Medicina del Deporte en tiempos del COVID}

\section{Pedro Manonelles}

Presidente de la Sociedad Española de Medicina del Deporte.

doi: 10.18176/archmeddeporte.0001

December 2019, and the Chinese city of Wuhan will not easily be erased from our memory, given that this is the starting point of the COVID-19 pandemic, a type 2 acute respiratory syndrome caused by the SARS-CoV2 virus.

In Spain, the first case was confirmed on 31st January 2020 in the island of La Gomera and the first death occurred on 13th February in Valencia'.

At this stage, the way of life of all citizens has had to adapt to this unexpected circumstance brought by fate, and Medicine and Sports Medicine are not external to this. Furthermore, at the time of writing this editorial, the pandemic is far from being under control.

The second outbreak of the pandemic, with a heterogeneous distribution, is characterised by its extensive spread, in many cases through certain groups, young people, leisure gatherings, many of a family nature and different types of crowds.

Although mortality has decreased and treatment appears to be more effective, the clinical picture frequently continues to be serious, and frequently lethal, with long stays in the ICU. On the other hand, the after-effects and complications of the disease are numerous and extremely important in many cases and this also affects athletes, even asymptomatic athletes, in which cardiomyopathies and other problems have been described, making it necessary to remain extremely vigilant ${ }^{2}$.

\section{Role of Sports Medicine in the context of the pandemic}

The role of Sports Medicine, represented by the Spanish Society of Sports Medicine (SEMED) is, at all times, to care for athletes and to help and protect the doctors working in this discipline.

Doctors, out of conviction and due to the very nature of their profession and their legal remit ${ }^{3}$, have the inexcusable obligation to "provide appropriate technical and professional healthcare to their patients", both from a therapeutic and preventive point of view. They are required to perform this duty even when this involves decisions that are not to the liking of patients or the population. To give a typical case, that of the amputation of a limb due to gangrene.

The Spanish Society of Sports Medicine, by virtue of its responsibility, has progressively taken decisions that are always in line with the situation of the pandemic. It has given an answer to citizens and professionals alike with regard to those matters that, due to its experience and knowledge, come within its competence. At the time of writing this editorial, the SEMED had published a total of eleven documents (announcements, action guidelines, recommendations and advice) specifically related to infection from the SARS-CoV2 virus, including matters concerning training, health promotion through physical activity, nutrition, sports practice, professional exercise and protection measures ${ }^{4}$.

The severe consequences of the pandemic has made it necessary to adopt measures directed at preventing the germ from spreading and the subsequent risk of infection. For this reason, the SEMED, through a group of experts from Society and with the close collaboration of the Consejo General de Colegios Oficiales de Médicos (General Council of the Official Association of Doctors), has been working on the preparation of the aforementioned documents.

There have been controversial recommendations related to the very nature of sports activities. Closeness and contact between athletes, rivals and also team mates, is inevitable in combat sports, team sports and racket sports (such as squash and padel for example), but also in individual sports in which closeness between athletes is a constant factor, as is the case of a pack of cyclists and long-distance runners, in canoeing and rowing (in team specialities), to give but a few examples. This closeness and contact promotes the transmission of the virus.

The other factor inherent in sport is ventilation. It was necessary to conduct an information campaign in order to explain the significance

Correspondencia: Pedro Manonelles

E-mail: pmanonelles@femede.es 
of ventilation, based on the location of a person at any given time, a phenomenon that is well known among sports doctors. For a normal adult, ventilation at baseline conditions is around 5-7 litres per minute. However, depending on the effort made, this respiratory flow not only increases with regard to the distance travelled by the exhaled air but also in volume, reaching 150-180 litres per minute for amateur athletes and up to 200-250 litres per minute for top level resistance athletes.

This fact has two extremely significant consequences. The first is that the social distancing recommendation of 1.5 metres is absolutely insufficient for sports activities. The second is the large amount of accumulated air that is breathed in by people in enclosed spaces in which sport or any other physical activity is practised, with little ventilation and the simultaneous presence of many people. If anyone is infected, even asymptomatically, then this will contaminate the air breathed in by this group and the disease will be transmitted.

In Sports Medicine it is well known that there is an intense focus on prevention (of injuries, of sudden death, etc.) and this is becoming the norm in daily professional practice. Evidence of this is the fact that a number of documents have been issued, setting out extensive measures to prevent the disease. For this reason, a recommendation was made, namely the use of face masks, which has created discontent in some sport sectors.

It is clear that the use of surgical face masks is a very important measure in the context of sports activities. In this way it is possible to limit the disease transmission and infection and, therefore, the use of face masks is recommended in non-professional and amateur sports.

Despite the fact that this pandemic has only recently appeared, scientific material is gradually becoming available and which serves to support the decisions that are being taken. With regard to the use of face masks, it can be said that no health risks have been found with regard to their correct, although continuous use. Although there is little evidence available on the matter, a study conducted on healthy adults 5 comparing the cardiorespiratory, metabolic, performance and comfort parameters in maximum effort tests while wearing either a surgical or FFP2 mask compared to that observed when no face mask was used found that the use of FFP2 face masks considerably reduced practically all the parameters studied, while the use of surgical face masks only affected some comfort parameters (heat, breathing resistance, itching, pressure, discomfort). The SEMED has initiated a similar study on athletes.

Although the SEMED has been criticised for making this recommendation, it is not the duty of doctors and their representative entities to either recommend or fail to recommend anything that is not acceptable to some members of society. Instead, based on their experience, evidence and responsibility, it is their duty to advise on what they consider to be the best way to protect health at all times.

\section{Bibliography}

1. https://es.wikipedia.org/wiki/Pandemia_de_COVID-19_en_Espa\%C3\%B1a;consultado 2/10/2020.

2. Nieß AM, Bloch W, Friedmann-Bette B, Grim C, Gärtner B, Halle M, Hirschmüller A, et al. RecommendationsforExerciseTesting in Sports Medicine during the CurrentPandemicSituation (SARS-CoV-2 / COVID-19). German J Sorts Med. 2000;5:E1-E2.

3. Ley $44 / 2003$, de 21 de noviembre, de ordenación de las profesiones sanitarias. BOE 280, 22 noviembre 2003:41442-58

4. Documentos de la Sociedad Española de Medicina del Deporte sobre el COVID-19. Disponibles en: http://femede.es/page.php?/Publicaciones/Covid19Deporte Consultado 10/10/2020.

5. Fikenzer S, Uhe T, Lavall D, Rudolph U, Falz R, Busse M, Hepp P, Laufs U. Response to the letter to the editor by Kampert, et al. entitled "Impact of wearing a facial covering on aerobic exercise capacity in the COVID-19 Era: is it more than a feeling?". Clin Res Cardiol. 2020 Aug 24:1. 